\title{
YUMIF dan Perubahan Sosial: Karakter, Komunikasi Strategis, dan Aktivasi Keterlibatan
}

\author{
Abdul Rohman \\ Dosen Program Studi Ilmu Komunikasi, Universitas Islam Indonesia
}

\begin{abstract}
Middle class in Indonesia is growing up but its interest is still inadequate in the political arena as the poor and the have. Mobilizing middle class to voice out their aspiration can trigger social change that might contribute to shift the horizon of democracy in the country. This paper brings preliminary conclusion on this issue: a) Indonesian middle class hypothetically falls into transitional spectrum between baby boomers and early millennial that is indicated by the essential meaning of family and self-sufficiency in their career, embracing short-medium orientation, and inclination to be rational in responding communication message compared to earlier generation (b) fit and multidirectional communication strategy, emphasizing on engagement and dialogue via effective communication channels to yield collaborative exchange are necessary, and (c) Indonesian YUMIF has strong economic-political power to bring social changes, therefore, empowering them to bring a better Indonesia is crucial.
\end{abstract}

Keywords: middle-class, social change, strategic communication

\begin{abstract}
Abstrak
Kelas menengah Indonesia sedang tumbuh tetapi kepentingan mereka belum mendapatkan ruang yang cukup di dalam agenda politik sebagaimana kelompok miskin dan atas.Menggerakkan mereka untuk bersuara di dalam pemilu mampu mendorong perubahan sosial yang dapat berkontribusi pada horizon demokrasi. Makalah ini membawa kesimpulan preliminer: a) berdasarkan telaah singkat tiga teori, YUMIF (Young Urban Middle Income Family) Indonesia memiliki karakteristik transisional antara baby-boomers dan millennial awal yang ditandai dengan pandangan pentingnya keluarga dan self-sufficiency pada karir dan independensi, orientasi menengah-pendek, dan cenderung rasional dalam merespon pesan komunikasi dibandingkan generasi sebelumnya sehingga (b) pemilihan strategi komunikasi yang fit perlu dilakukan secara multiarah, mengedepankan prinsip keterlibatan dan dialog melalui variasi saluran yang efektif untuk mencapai pertukaran kolaboratif; dan (c) YUMIF Indonesia memiliki kekuatan ekonomi-politik yang kuat untuk membawa perubahan sosial sehingga memberdayakan mereka untuk membawa Indonesia menjadi lebih baik adalah sangat penting.
\end{abstract}

Kata kunci: Kelas Menengah, Perubahan Sosial, Komunikasi Strategis 


\section{Pendahuluan}

Dewasa ini, kelas menengah mendapat perhatian lebih di media.Ini terlihat dari banyaknya, sebagai contoh, iklan di televisi yang menampilkan profesional muda, ibu rumah tangga perkotaan, dan keluarga muda dengan budaya dan sosial yang berbeda dengan kelompok miskin atau pun kelompok kelas atas di Indonesia. Bukan hanya itu, sejumlah pusat perbelanjaaan dan gerai merek terkemuka kini juga dapat dengan mudah ditemukan dan dipenuhi oleh mereka yang tengah mananjaki kelas sosial tertentu.Warung cepat saji Amerika yang banyak dipersepsikan sebagai simbol gengsi hampir tidak pernah sepi dan malah menjadi salah satu pilihan untuk merayakan ulang tahun anak-anak.

Meskipun fenomenanya dapat secara jelas diamati, terdapat variasi dalam mendefinisikan kelas menengah pendekatan pluralist, Weberian, ideologisosio kultural, dan sebagainya.Untuk maksud makalah ini, kelas menengah didefinisikan dengan pendekatan pluralis yang seringkali didasarkan pada pendapatan, pengeluaran, pola konsumsi, dan psikografis. Tabel 1 Klasifikasi Kelas Menengah berdasarkan Pengeluaran di bawah mendeskripsikan kelas menengah Indonesia berdasarkan pengeluaran perhari: a) kelas menengah - bawah dengan pengeluaran berkisar USD 2 - 4 atau IDR 20000 - 40000, b) menengah menengah antara USD 4 - 10 atau IDR 41000 - 100000, dan c) menengah - atas mereka yang berpengeluaran antara USD 10 - 20 perhari atau IDR 101000 20000o. Ini menunjukkan bahwa kategori pertama mendominasi nyaris 35\% dari total populasi, disusul dengan kategori 2 dan 3, masing-masing mendekati $11 \%$ dan 1\% lebih sedikit. Secara keseluruhan, jumlah total kelas menengah Indonesia adalah sekitar $46 \%$ dari total populasi atau lebih dari 100 juta orang dengan total pengeluaran sekitar 67 milyar pada tahun 2005 dan angka ini secara positif diprediksi meroket (Indonesianconsume; 2013; Supriyatna, 2013).

Tabel 1. Klasifikasi Kelas Menengah berdasarkan Pengeluaran

\begin{tabular}{|c|c|c|c|c|c|c|c|c|c|}
\hline $\begin{array}{l}\text { \% dari Populasi } \\
\text { (2005, PPP) }\end{array}$ & Total & $\$ 20+$ & $\begin{array}{l}\text { Total Populasi } \\
\text { (2005, Juta) }\end{array}$ & Total & $\$ 20+$ & $\begin{array}{l}\text { Pengeluaran } \\
\text { Tahunan } \\
(2005 \text {, billion }\end{array}$ & & Total & $\$ 20+$ \\
\hline$\$ 2-\$ 4 \$ 4-\$ 10 \$ 10-\$ 20$ & & & $\$ 2-\$ 4 \quad \$ 4-\$ 10 \$ 10-\$ 20$ & & & $\$ 2-\$ 4 \quad \$ 4-\$ 10$ & $\$ 10-\$ 20$ & & \\
\hline $34.9610 .46 \quad 1.16$ & 46.58 & .26 & $77.10 \quad 23.07$ & 102.72 & .58 & $37.71 \quad 22.98$ & 5.57 & 66.56 & 3.86 \\
\hline
\end{tabular}

Sumber: Data Bank Dunia 2010 yang telah diolah oleh Penulis 
Abdul Rohman, YUMIF dan Perubahan Sosial: Karakter, Komunikasi Strategis, dan Aktivasi Keterlibatan

Kelas menengah di Indonesia, atau Asia Tenggara secara umum, memiliki kekuatan dalam sejarah politik sebagaimana diungkap oleh (Robinson, 1995). Kajian lain tentang sosio-kulturalekonomi-politik kelas menengah di China, India, dan beberapa negara berkembang lain seperti Israel dan Brazil dapat ditelaah melalui kerja (Li, 2010; Jaffrelot \& Veer, 2008; Lange \& Meier, 2009). Kelas menengah juga dianggap sebagai titik balik dari perubahan perpolitikan di Amerika Serikat (Dechter, 2012). Berangkat dari sejumlah poin dalam data di atas dan kajian tersebut, makalah ini memfokuskan pada Young Urban Middle Income Family (YUMIF) sebagai satu kategori kelas menengah kemudian mengargumentasikan pendekatan komunikasi strategis untuk mengaktivasi kategori ini dan menghubungkannya dengan potensi perubahan.

\section{Pembahasan}

\section{Karakter YUMIF Indonesia}

YUMIF Indonesia perlu mendapatkan perhatian lebih karena kekuatan ekonomi politik yang mereka punya sebagaimana terpaparkan dalam survey Consumer3ooo.net (2013) danIndonesianconsume (2013). Meski demikian, kelas ini bukan mudah untuk didekati. Untuk memproduksi strategi dan taktik pendekatan yang efisien, efektif, and ekuitable, mempelajari karakteristiknya adalah sangat penting.

YUMIF ditandai dengan beresidensi di perkotaan, pasangan muda, keluarga kecil dengan anak di bawah tiga, berpendidikan, dan memiliki pekerjaan mapan. Sejumlah kajian tentang konsumen di Indonesia mengindikasikan bahwa kelompok ini menggambarkan Indonesia saat ini. Salah satu contoh adalah laporan Nielsen (2013) yang menyebut Indonesia sebagai negara yang perlu diperhatikan setelah 3 negara besar (Amerika Serikat, Jerman, dan Jepang) dan BRIC (Brazil, Rusia, India, dan China). Berbeda dengan laporan sejenis yang telah ada, seksi ini mengeksplorasi YUMIF dari lensa tiga teori: psikoanalisis (psychoanalysis theory), peneguhan (reinforcement theory), dan kognitif (cognitive theory). Telaah teoretis ini esensial untuk memberikan titik berangkat bagi perencana komunikasi dan perubahan dalam menentukan strategi yang relevan pada YUMIF dan menurunkan taktik yang tepat untuk mengaktivasi mereka sebagai agen perubahan. Masing-masing teori dan deskripsinya terelaborasi pada Tabel 2 berikut: 
Tabel 2. YUMIF dari Lensa Teori

\begin{tabular}{|c|c|c|}
\hline Teori & Penjelasan inti & YUMIF \\
\hline Psikoanalisis & $\begin{array}{l}\text { Teori ini menekankan individu } \\
\text { bertindak berdasarkan pemi- } \\
\text { kiran di bawah kesadaran yang } \\
\text { terbentuk karena pengaruh } \\
\text { ayah, ibu, atau saudara. } \\
\text { Tindakan yang diambil meru- } \\
\text { pakan aktivasi dari faktor- } \\
\text { faktor internal tersebut. }\end{array}$ & $\begin{array}{l}\text { Median usia penduduk Indonesia adalah } 29 \\
\text { tahun (Nielsen, 2013) atau lahir di awal 80- } \\
\text { an. Generasi ini tumbuh dengan MTV dan } \\
\text { mereka masih merengkuh nilai-nilai } \\
\text { tradisional yang diteruskan oleh baby } \\
\text { boomers. Meski demikian, mereka juga } \\
\text { dapat terkategori sebagai generasi awal } \\
\text { millenial yang cenderung menjaga privasi, } \\
\text { independen, memiliki lingkaran pergaulan } \\
\text { relatif tidak besar tetapi kuat, dan career } \\
\text { oriented tanpa melupakan nilai-nilai } \\
\text { keluarga. Meskipun memiliki pendidikan } \\
\text { cukup, YUMIF bisa jadi masih merespon } \\
\text { informasi sedikit sama dengan baby- } \\
\text { boomers secara kultural dan sosiologis. }\end{array}$ \\
\hline Penę & $\begin{array}{l}\text { Teori ini menyebut individu } \\
\text { bertindak karena mereka } \\
\text { mengetahui apa akibat dari } \\
\text { tindakannya (keuntungan, } \\
\text { kerugian, atau netral). }\end{array}$ & $\begin{array}{l}\text { Meskipun secara kultural Indonesia adalah } \\
\text { kolektivistik, YUMIF memiliki karakteristik } \\
\text { masyarakat urban lainnya seperti bagian } \\
\text { dunia manapun dimana nuansa } \\
\text { transaksional lebih mendominasi } \\
\text { dibandingkan relasional. YUMIF lebih peka } \\
\text { terhadap hasil jangka pendek/menengah } \\
\text { (short/medium oriented) dan kurang } \\
\text { antusias pada orientasi jangka panjang. } \\
\text { Dengan kata lain, YUMIF menginginkan } \\
\text { hasil konkret, tampak, dan cenderung } \\
\text { resisten pada keabstrakan. Selain itu, } \\
\text { YUMIF adalah konsumen/warga negara } \\
\text { yang rasional karena ketercukupan } \\
\text { pendidikan, kemampuan mengakses dan } \\
\text { mengambil benefit dari informasi. }\end{array}$ \\
\hline Kognitif & $\begin{array}{lr}\text { Teori ini menjelaskan } & \text { bahwa } \\
\text { penggunaan dan } & \text { proses } \\
\text { informasi pada individu } & \text { ini } \\
\text { dipengaruhi oleh } & \text { faktor } \\
\text { eksternal dan internal dengan } \\
\text { lingkungan dan } & \text { faktor } \\
\text { personal di dirinya. } & \end{array}$ & $\begin{array}{l}\text { Sebagaimana tersebutkan di atas, YUMIF } \\
\text { sekarang adalah transisi dari akhir baby- } \\
\text { boomers dan millenial, mereka cenderung } \\
\text { melakukan hibridisasi pada informasi } \\
\text { dengan mengombinasikan beragam sumber } \\
\text { dan media meskipun dalam konteks ini } \\
\text { komunikasi interpersonal masih memiliki } \\
\text { kredibilitas tertinggi dibandingkan lainnya. } \\
\text { Pengambilan keputusan YUMIF bukan } \\
\text { hanya pertimbangan nilai-nilai keluarga } \\
\text { tetapi juga keputusan rasional yang } \\
\text { menghitung cost-benefit secara seksama. }\end{array}$ \\
\hline
\end{tabular}

Sumber: Teori diidentifikasi oleh C Fill (2009) dan psikografis YUMIF oleh penulis. 
Abdul Rohman, YUMIF dan Perubahan Sosial: Karakter, Komunikasi Strategis, dan Aktivasi Keterlibatan

2. Aktivasi Keterlibatan Melalui Pendekatan Komunikasi Strategis

Tabel 2 di atas secara sederhana dapat dijadikan sebagai batu loncatan untuk menganalisis pengambilan keputusan YUMIF yang secara sederhana diilustrasikan pada Grafik 1 Pengambilan Keputusan YUMIF dan Lingkungan Terkait. Tampak pada grafik bahwa pengambilan keputusan mendapatkan faktor penjelas yang beragam seperti budaya, agama, kelas sosial, dan lain-lain yang terasosiasi. Tahapan sekuensial -dan tidak bergantung tingkat keterlibatanseperti di grafik dapat dipengaruhi oleh komunikator melalui ketersediaan saluran, tujuan, dan pilihan strategi komunikasi seperti pull, push, profile, ataupun kombinasi di antara itu. Memahami ini melalui analisis terhadap data dan fakta yang ada, perencana komunikasi strategis dapat mendesain pesan yang fit (kesesuaian antara kebutuhan, sumber daya, dan karakter) untuk menjangkau YUMIF.

Faktor-faktor penjelas berinteraksi dengan alur pengambilan keputusan individu dari kondisi yang telah ada dan pengetahuan yang dimiliki dapat berimplikasi pada proses penginderaan seseorang pada pilihan yang tersedia. Pada tahapan ini sejumlah premis tentang masa depan dan pengalaman masa lalu dapat bertubrukan yang dapat memunculkan keputusan baru, pengukuhan, ataupun pengeluaran pilihan tertentu dari daftar yang dimiliki individu. Dengan kata lain, konfrontasi ini dapat mengaksentuasi, mereduksi, memodifikasi, ataupun mengeleminasi pilihan yang memungkinkan untuk dieksekusi. Setelahnya, seseorang pun dapat melakukan penilaian atas pilihannya ini hingga pada level tertentu dia dapat memberikan rekomendasi positif atau pun negatif kepada orang lain.

Dengan mempertimbangkan loop ini, komunikator dapat mengintervensi preferensi komunikan melalui infiltrasi pesan dengan pertimbangan komprehensif pada ketersediaan saluran komunikasi yang diprediksi dapat berdampak pada seseorang. Seorang perencana media dan komunikator strategis sangat familiar dengan ini, hanya saja di tengah hiruk pikuk saluran yang ada perlu sangat memperhatikan mana yang paling fit untuk sasarannya dan hasil komunikasi yang diantisipasi bersesuaian dengan strategi yang dipilihnya.

Dengan mempertimbangkan hal ini, Tabel 3 kemudian menyediakan opsi level dan metode komunikasi yang dapat digunakan untuk menjangkau YUMIF dengan nuansa pertukaran transaksional dan kolaboratif sebagai sebuah kontinum. Pendekatan ini tidak ingin mendikotomikan dua kutub dalam garis pertukaran, tetapi mem-berikan ruang yang cukup untuk komunikator mendesain strategi dan taktik pada titik tertentu sesuai dengan ketersediaan sumber daya dan karakteristik komunikan 
yang ingin disasar. Semakin kolaboratif pertukaran yang diharapkan, komunikasi semakin penting mengedepankan keterlibatan dan dialog dengan jejaring yang ada.Di dalam konteks YUMIF yang dibahas di dalam makalah ini, komunikator perlu menekankan komunikasi multiarah dan meletakkan YUMIF bukan hanya sebagai sasaran, tetapi sekaligus pelaku dari aktivitas/program komunikasi.

Sebagai contoh, YUMIF yang tergabung di dalam komunitas tertentu cenderung ingin terlibat dalam aktivasi komunitasnya melalui tindakan-tindakan kontributif sebagai upaya memenuhi selfesteem sebagai anggota. Pesan komunikasi yang acapkali dimulai dengan penumbuhan kesadaran, pengetahuan, dan perilaku dapat dimodifikasi sesuai situasi yang paling tepat. Misalkan, pendekatan edukasi masih penting, tetapi YUMIF secara psikologis cenderung merasa telah tahu dan tidak ingin digurui sehingga mengorganisasikan mereka untuk bertindak secara terpola menjadi lebih feasible. Selanjutnya, ini dapat dikembangan secara kuantitas dan kualitas untuk berevolusi menjadi kebiasaan berdampak yang dapat bermultiplikasi menjadi perubahan sosial.Dalam jangka medium, sejumlah tindakan yang dilakukan bersamasama/ serentak dapat dipersepsikan sebagai sebuah tren yang membiasa sehingga dampak yang diharapkan pun dapat terukur. Bisa jadi ini adalah sangat relevan dengan karakteristik masyarakat Indonesia secara umum yang lebih menginginkan tindakan konkret secara masif meskipun kedalaman penerimaan/ hasil komunikasi memerlukan tindakan lanjutan.

\section{Tabel 3. Pertukaran dan Pendekatan Komunikasi}

\begin{tabular}{|c|c|c|c|c|}
\hline \multirow[t]{2}{*}{$\begin{array}{l}\text { Transaksional } \\
\text { kolaboratif }\end{array}$} & \multicolumn{4}{|c|}{$\longleftrightarrow$ relasional } \\
\hline & $\begin{array}{l}\text { Komunikasi } \\
\text { massa }\end{array}$ & $\begin{array}{l}\text { Komunikasi massa- } \\
\text { customized }\end{array}$ & $\begin{array}{l}\text { Dialogue - } \\
\text { engagement }\end{array}$ & $\begin{array}{l}\text { Jejaring } \\
\text { komunikasi } \\
\text { bermediasi } \\
\text { tehnologi }\end{array}$ \\
\hline $\begin{array}{l}\text { Komunikasi } \\
\text { multiarah/interaktif }\end{array}$ & & & & \\
\hline $\begin{array}{l}\text { Komunikasi dua } \\
\text { arah }\end{array}$ & & & & \\
\hline $\begin{array}{l}\text { Komunikasi satu } \\
\text { arah }\end{array}$ & & & & \\
\hline
\end{tabular}

Sumber: Dari Berbagai Sumber, Tabel oleh Penulis 
Abdul Rohman, YUMIF dan Perubahan Sosial: Karakter, Komunikasi Strategis, dan Aktivasi Keterlibatan

Pembahasan yang ada tentang komunikasi baik yang masih umum maupun yang telah dimodifikasi sesuai kebutuhan audiens dirasa telah cukup dan makalah ini lebih mengadvokasi pentingnya dialog-keterlibatan dan inisiasi/pengembangan jejaring komunikasi bermediasi teknologi. Meskipun kelas menengah memiliki level kecukupan informasi yang bervariasi, secara psikologis mereka tidak ingin diposisikan lebih rendah dibandingkan dengan kelompok lain. Oleh karenanya, prinsip dialog dimana asumsi bahwa setiap partisipan komunikasi adalah setara menjadi esensial untuk mencapai hasil yang diharapkan. Pesan komunikasi dengan prinsip dialog ini dapat menggunakan pilihan pesan yang telah dipersonalisasikan pada aspek tertentu, juga dapat memilih satu isu yang dianggap sebagai masalah bersama. Contoh yang pertama dapat terlihat pada taktik pemilihan kata ganti orang: apakah menggunakan "Anda" atau "Kita." Pilihan yang pertama bisa menjadi bentuk personalisasi suatu masalah yang bisa berdampak pada diri setiap orang. YUMIF sangat peduli pada kepentingannya dan sangat dengan mudah menidakprioritaskan kepentingan orang lain. Pilihan yang kedua bisa dirujuk untuk melihat YUMIF sebagai kategori yang lebih besar dalam analisis ekonomi politik, misalkan bagaimana kenaikan harga gas dapat berdampak pada manajemen kesejahteraan keluarga kecil mereka. Secara singkat, pemilihan personalisasi ini perlu menegaskan pada bagaimana setiap pesan komunikasi untuk isu yang relevan dapat berdampak pada kepentingan YUMIF, baik sebagai individu ataupun kelompok.

Sebagian besar YUMIF memiliki preferensi tehnologi sebagai jembatan atau saluran komunikasi. Telepon pintar dan piranti teknologi komunikasi yang lain juga menjadi pilihan dalam pencarian, penggunaan, dan penyebaran informasi yangdimiliki oleh YUMIF. Dengan kata lain, senada dengan penjelasan pada proses pengambilan keputusan, anggota YUMIF juga dapat dipengaruhi dengan menggunakan saluran ini. Akan tetapi, level komunikasi antarpribadi masih dapat dikatakan masih lebih kredibel dibandingkan tingkatan lainnya. Singkatnya, meskipun familiar dengan teknologi, YUMIF tetap menaruh kepercayaan komunikasi antar pribadi, tetapi pembedaan kedalaman dan keluasan dalam pertukaran pesan dapat berpindah dimensi dari offline ke online, atau sebaliknya tanpa memerlukan prosedur yang rigid. 


\section{Grafik 1. Pengambilan Keputusan YUMIF dan Lingkungan Terkait}

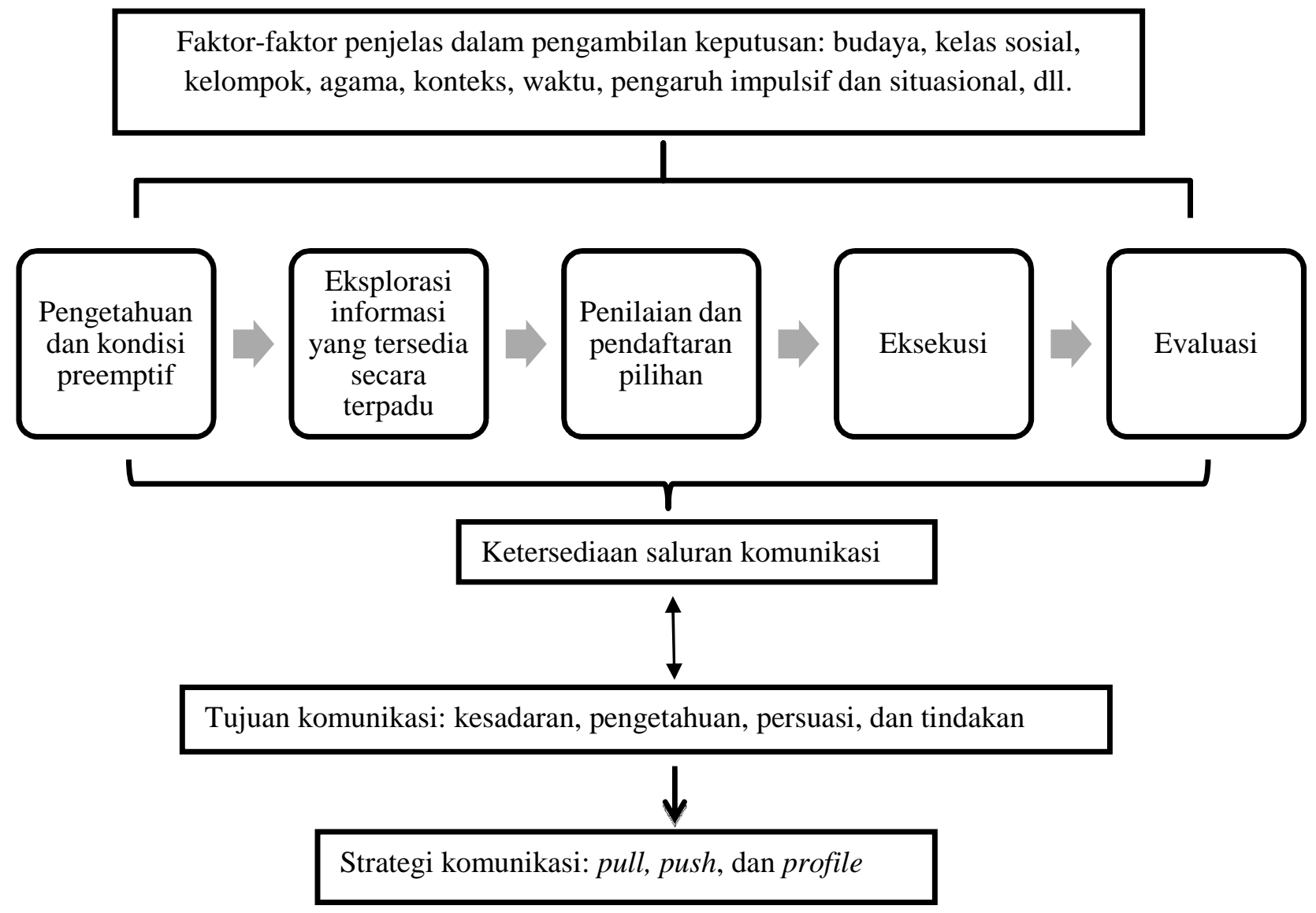

Sumber: Dari berbagai sumber, grafik oleh penulis.

\section{Kesimpulan}

Secara

umum

$-\operatorname{tanpa}$

mensimplifikasikan horizon nyata yang ada- YUMIF dapat mempengaruhi status perubahan secara ekonomi, sosial-budaya, dan politik di Indonesia.Jika dikaitkan dengan Pemilu 2014, selain pemilih pemula, investasi pada YUMIF dapat menjadi salah satu kunci untuk membawa perubahan sosial.YUMIF cenderung meningkat kesadaran terhadap hakhaknya sebagai warga negara semakin rasional untuk (tidak) menggunakan hak pilihnya pada kandidat tertentu. Di sisi lain, jika kandidat yang berkompetisi mampu mengekspos kepentingan YUMIF dengan pendekatan komunikasi yang efektif, mereka bisa jadi mendapatkan hasil yang diharapkan dalam pemilu mendatang.

Makalah ini membawa kesimpulan preliminer -sangat terbuka untuk invesitigasi lebih lanjut- bahwa:

a) berdasarkan telaah singkat tiga teori, YUMIF Indonesia memiliki karakteristik transisional antara babyboomers dan millennial awal yang ditandai dengan pandangan pentingnya keluarga dan self-sufficiency seperti karir dan independensi, orientasi 
Abdul Rohman, YUMIF dan Perubahan Sosial: Karakter, Komunikasi Strategis, dan Aktivasi Keterlibatan

menengah-pendek, dan cenderung rasional dalam merespon pesan komunikasi disbanding-kan generasi sebelumnya.

(b) pemilihan strategi komunikasi yang fit perlu dilakukan dengan sentuhan multiarah, mengedepankan prinsip keterlibatan dan dialog melalui variasi saluran yang efektif untuk mencapai pertukaran kolaboratif antara komunikator dan YUMIF;

(c) YUMIF Indonesia memiliki kekuatan ekonomi-politik yang kuat untuk membawa perubahan sosial sehingga memberdayakan mereka sangat penting untuk membawa Indonesia menjadi lebih baik.

\section{Daftar Pustaka}

Consumer300o.net. 2013, Perilaku Kelas Menengah dalam Produk Finansial. Retrieved Oktober 25, 2013, from Consumer300o.net: http://consumer3000.net/asset -management/warninghtmlspecialchars-functionhtmlspecialchars-charset-utf-7not-supported-assuming-iso8859-1-inhomek2742069public htmlwpincludesformatting-php-online-2751warninghtmlspecialch-2/

Fill, C. 2009. Marketing Communications. Interactivity, Communities, and Contents. Fifth Edition. UK: Prentice Hall.

Indonesianconsume. 2013. Indonesianconsume.blogspot.c om. Retrieved Oktober 25, 2013, from Indonesian Consume:

http://indonesianconsume.blog spot.com/2013/03/indonesia2020-141-juta-kelasmenengah.html\#.UmnhNnCnq $7 \mathrm{~A}$
Indonesianconsume. 2013. Perilaku Kelas Menengah Indonesia Berubah. Retrieved Oktober 25, 2013, from Indonesianconsume.blogspot.net : http://indonesianconsume. blogspot.com/2013/o3/perilakukonsumen-kelasmenengah.html\#.UmnkdnCnq7 $\underline{\mathrm{A}}$

Jaffrelot, C., \& Veer, P. v. 2008. Patterns of Middle Class Consumption in India and China. New Delhi: Sage Publication.

Lange, H., \& Meier, L. 2009. The New Middle Classes. Globalizing Lifestyle, Consumerism, and Environmental Concerns. New York: Springer.

Li, C. 2010. China's Emerging Middle Class. Beyond Economic Transformation. Washington, DC: The Brookings Institution. 
Nielsen. 2013. Middle Class. State of Mind or Share of Wallet? Spending Flexibility around the World During Inflamatory Time. Nielsen.

Robinson, R. 1995. Working Paper. Emergence of Middle Class in South East Asia. Western Australia: Asia Research Center. Murdoch University.
Supriyatna, I. 2013 Economy: Fiskal dan Moneter. Retrieved Oktober 25, 2013, from Okezone.com: http://economy.okezone.com/ $\mathrm{read} / 2012 / 04 / 28 / 20 / 620129 /$ kelas-menengah-di-indonesiabertambah 